\title{
Rescue of Axotomized Immature Rat Facial Motoneurons by $R(-)$-deprenyl: Stereospecificity and Independence from Monoamine Oxidase Inhibition
}

\author{
K. S. Ansari, ${ }^{1,3}$ P. H. Yu, ${ }^{4}$ T. P. A. Kruck, ${ }^{1,3}$ and W. G. Tatton ${ }^{1,2,3}$ \\ ${ }^{1}$ Departments of Physiology and ${ }^{2}$ Psychiatry, and the ${ }^{3}$ Centre for Research in Neurodegenerative Diseases, University of \\ Toronto, Toronto, Ontario, M5S 1 A8 Canada and the ${ }^{4}$ Neuropsychiatric Research Unit, University of Saskatchewan, \\ Saskatoon, Saskatchewan, S7N OWO Canada
}

The role of monoamine oxidase $B$ (MAO-B) in $\boldsymbol{R}(-)$-deprenyl-mediated rescue of rat facial motoneurons axotomized at postnatal day 14 (P14) was investigated using the $(+)$ - and (-)-enantiomers of deprenyl [S(+)-deprenyl and $\boldsymbol{R}(-)$-deprenyl]. Previously, doses of $\boldsymbol{R}(-)$-deprenyl sufficient to inhibit MAO-B were shown to increase the survival of motoneurons following an apparent loss of target-derived trophic support caused by axotomy in P14 rats. In the present experiments, motoneuronal survival was measured 21 d after unilateral facial nerve transection at P14. The animals were treated with saline or doses of $R(-)$ - or $\boldsymbol{S}(+)$-deprenyl ranging from 0.001 to $10 \mathrm{mg} / \mathrm{kg}$ every 2 days (/2d). Frontal serial $10 \mu \mathrm{m}$ sections were taken through the length of the facial nuclei ipsilaterally and contralaterally to the facial nerve transections. Every third section was immunoreacted for an antibody against ChAT to identify the motoneuron somata, while every adjacent third section was Nissl stained to assess motoneuronal survival. A second series of P14 rats was treated with similar doses of the two deprenyl enantiomers or saline and the brainstems removed for measurement of MAO-A and MAO-B activity at $4 \mathrm{hr}$ after the treatments.

Averages of $24 \%$ of the facial motoneurons survived axotomy with either saline treatment or $0.001 \mathrm{mg} / \mathrm{kg} / 2 \mathrm{~d}$ doses of $\boldsymbol{R}(-)$-deprenyl. Doses of $\boldsymbol{R}(-)$-deprenyl of $0.005,0.01$, and $10.0 \mathrm{mg} / \mathrm{kg} / \mathbf{2 d}$ increased the surviving facial motoneuron to $38 \%, 51 \%$, and $48 \%$, respectively, indicating an $E D_{50}$ of about $0.005 \mathrm{mg} / \mathrm{kg} / 2 \mathrm{~d}$. Doses of $\boldsymbol{S}(+)$-deprenyl as high as $10 \mathrm{mg} / \mathrm{kg} / 2 \mathrm{~d}$ did not increase motoneuronal survival, revealing a stereospecificity for the increased survival of at least 2000-fold. The $E_{50}$ for MAO-B inhibition in the P14 brainstem was approximately $0.1 \mathrm{mg} / \mathrm{kg}$ for the $(-)$-enantiomer and $2.0 \mathrm{mg} / \mathbf{k g}$ for the (+)-enantiomer, revealing a 20-fold higher sensitivity of the enzyme toward the (-)-enantiomer in the P14 rat brainstem. A dose of $10 \mathrm{mg} / \mathrm{kg}$ of $S(+)$-deprenyl inhibited about $65 \%$ of brainstem MAO-B activity without increasing motoneuronal survival, whereas 0.005

\footnotetext{
Received Oct. 26, 1992; revised Mar. 26, 1993; accepted Apr. 7, 1993.

We gratefully acknowledge Mae Kwan, Dianne Holland, Helen Huang, and Lisa Shira-Bock for their excellent technical assistance. Fred Zhang aided in the preparation of the animals. This work was supported by grants from the Parkinson's Foundation of Canada, Ciba Geigy of Canada Ltd., and a pilot grant from the Amyotrophic Lateral Sclerosis (ALS) Society of Canada. K.S.A. was supported by a scholarship from the Gibson Foundation.

Correspondence should be addressed to Dr. William G. Tatton, Centre for Research in Neurodegenerative Diseases, University of Toronto, 6 Queen's Park Crescent West, Toronto, Ontario M5S 1A8 Canada.

Copyright (C) 1993 Society for Neuroscience $0270-6474 / 93 / 134042-12 \$ 05.00 / 0$
}

and $0.01 \mathrm{mg} / \mathrm{kg}$ of $\boldsymbol{R}(-)$-deprenyl increased motoneuronal survival without significant inhibition of brainstem MAO-B activity. The dosage relationships for motoneuronal rescue versus MAO-A and MAO-B inhibition and the marked difference in the stereospecificity of MAO-B inhibition versus that of motoneuronal rescue show that the increased survival is unlikely to be dependent on the interaction of deprenyl with the FAD site of MAO-A or MAO-B, and instead appears to depend on a stereospecific interaction at an as yet unknown site.

[Key words: axotomy, motoneuron, stereospecificity, deprenyl, monoamine oxidase, rescue]

$R(-)$-deprenyl ( $\mathrm{L}$-deprenyl or selegiline) is a typical selective inhibitor of monoamine oxidase (MAO) type B, an enzyme that preferentially deaminates phenylethylamine and benzylamine. The functionally different forms of MAO, denoted " $A$ " and " $B$," were first reported by Johnston (1968). The molecular differences between these two enzymes derive from differences in their primary amino acid sequences (Bach et al., 1988) in that they are encoded by separate gene loci (sec Shih, 1991). Deprenyl binds to MAO-B and irreversibly inhibits the enzyme, similarly to other suicidal inhibitors in the flavin adenine dinucleotide (FAD)-binding class of compounds (see (Youdim, 1978).

$R(-)$-deprenyl was reported by Birkmayer et al. (1975) to increase the efficacy of levodopa therapy in the treatment of Parkinson's disease (PD) by reducing dopamine (DA) catabolism by MAO-B (Birkmayer et al., 1983). More recently, $R(-)$ deprenyl monotherapy has been reported to slow the progression of neurological deficits in PD (Parkinson Study Group, 1989, 1993; Tetrud and Langston, 1989; Poungvarin and Viriyavejakul, 1990; Allain et al., 1991; Myllylä et al., 1992) and cognitive decline in Alzheimer's disease (AD) (Sunderland et al., 1987; Tariot et al., 1987; Campi et al., 1990; Falsaperla et al., 1990; Monteverde et al., 1990; Piccinin et al., 1990; Goad et al., 1991; Mangoni et al., 1991; Martignoni et al., 1991; Schneider et al., 1991).

The extent of the beneficial effects of $R(-)$-deprenyl treatment in the two neurodegenerative diseases is controversial and the mechanisms underlying those benefits are unknown. The apparent slowing of the two diseases has been variously ascribed to (1) symptomatic actions caused by a decrease in DA catabolism resulting from the inhibition of MAO-B (see Lieberman et al., 1992) or by a facilitation of DA transmission by 2-phenylethylamine (2-PEA) (Paterson et al., 1990a,b), (2) protection of neurons against toxic oxidative damage through the reduction of free radical formation (see Olanow and Calne, 1992), or (3) the CNS stimulant effect caused by the major catabolic 
products of $R(-)$-deprenyl, (-)-amphetamine, and (-)-methamphetamine (Karoum et al., 1982; Engberg et al., 1991).

A previously unrecognized action of $R(-)$-deprenyl also might contribute to the beneficial effects in PD and AD. $R(-)$-deprenyl can increase the survival of damaged neurons or rescue them rather than just protect neurons from sustaining oxidative damage as previously supposed (see Tatton, 1993, for a recent review). Experiments in mice showed that $R(-)$-deprenyl increases the survival of dopaminergic nigrostriatal neurons (dNSns) damaged by the parkinsonian toxin MPTP (Tatton and Greenwood, 1991), independently of blocking the conversion of MPTP to $\mathrm{MPP}^{+} . R(-)$-deprenyl reduced the death of dNSns by $60-$ $70 \%$ when treatment was delayed for $72 \mathrm{hr}$ after the completion of MPTP exposure. The delay in $R(-)$-deprenyl treatment allowed time for the complete conversion of MPTP to MPP+ (Yang et al., 1988) and for extensive damage to dNSns by the toxin (Linder et al., 1987).

$R(-)$-deprenyl also increases the survival of motoneurons after axotomy produced by facial nerve transection at postnatal day 14 (P14) (Salo and Tatton, 1992). The motoneuronal death after facial nerve transection is thought to reflect the dependency of the immature motoneurons on trophic support that is axonally transported from the facial muscles (Crews and Wigston, 1990). Reductions in motoneuronal death can be produced when neurotrophic factors like ciliary neurotrophic factor (CNTF) (Sendtner et al., 1990), brain-derived neurotrophic factor (BDNF) (Sendtner et al., 1992; Yan et al., 1992), or basic fibroblast growth factor (bFGF) (Grothe and Unsicker, 1992) are provided to the cut axons of the motoneuron.

Whether the $R(-)$-deprenyl-mediated reduction in motoneuron death involves MAO-B or MAO-A inhibition is uncertain. Doses of $10 \mathrm{mg} / \mathrm{kg} / 2 \mathrm{~d}$ of $R(-)$-deprenyl were used to rescue the immature facial motoneurons after axotomy (Salo and Tatton, 1992). Those doses would cause greater than $70 \%$ inhibition of $\mathrm{MAO}-\mathrm{B}$, and some MAO-A inhibition as well, in adult rodents (Demarest et al., 1980). The $\mathrm{ED}_{50}$ for MAO-B inhibition is 0.5 $\mathrm{mg} / \mathrm{kg}$ in the adult rodent (Yu et al., 1992). In vitro studies using newborn mouse cortex have shown decreased MAO-B activity relative to $\mathrm{MAO}-\mathrm{A}$ activity when compared to the relative activity of the enzymes in adult cortical tissue ( $\mathrm{Yu}$ and Hertz, 1982). A similar increase in sensitivity of MAO-B activity to deprenyl inhibition in the immature $P 14$ brainstem would result in significant $\mathrm{MAO}-\mathrm{B}$ inhibition by doses of $R(-)$-deprenyl that are insufficient to inhibit $\mathrm{MAO}-\mathrm{B}$ in adult rodents.

We compared the MAO-A and MAO-B inhibition produced by the $(+)$ - and the (-)-enantiomers of deprenyl in the P14 rat brainstem with the ability of the two enantiomers to increase facial motoneuronal survival after axotomy at P14. The dosage relationships and the differences in the stereospecificity of MAO-B inhibition versus that of the increased motoneuronal survival showed that the increased survival is not mediated by the binding of $R(-)$-deprenyl, at the FAD site, of MAO-B that causes inhibition of the enzyme.

\section{Materials and Methods}

Facial nerve transection. Sprague-Dawley rats at P14 (Charles River Laboratories) were anesthetized using $4.0 \%$ halothane for induction and $1.0-1.5 \%$ halothane for maintenance in an atmosphere consisting of $30 \% \mathrm{O}_{2}$ and $70 \% \mathrm{~N}_{2} \mathrm{O}$ supplied at a flow rate of 4 liters $/ \mathrm{min}$. The right facial nerve was transected immediately distal to its exit from the stylomastoid foramen. Care was taken to remove a $4 \mathrm{~mm}$ segment of the nerve in order to prevent reinnervation of the distal nerve stump. After surgery, the animals were given either $S(+)$-deprenyl, $R(-)$-deprenyl, or vehicle (saline) intraperitoneally, acutely, and then every other day thereafter for $21 \mathrm{~d}$. On the 21 st day after the axotomy (P35), the animals were killed and perfused with $4 \%$ paraformaldehyde.

After removal, the brainstem was cryoprotected in $20 \%$ sucrose and frozen in $-70^{\circ} \mathrm{C}$ methylbutane. Serial $10 \mu \mathrm{m}$ sections were cut through the entire length of the facial nucleus and every third section was incubated overnight with a polyclonal antibody directed against ChAT $(1: 1000)$ at $4^{\circ} \mathrm{C}$. The sections were then incubated in biotinylated goat anti-rabbit IgG and then with avidin-horseradish peroxidase (HRP). The visualization of immunoreactive cells was performed in a $0.05 \%$ solution of diaminobenzidine in $0.01 \% \mathrm{H}_{2} \mathrm{O}_{2}$. Controls were carried out by incubating sections in nonimmune serum instead of primary antiserum.

The ChAT immunoreaction was used to unambiguously recognize motoneuron somata in the facial nucleus. Consecutive sections immediately adjacent to those that were ChAT immunoreacted were stained for Nissl substance in order to determine whether the numbers of Nisslstainable somata were the same as the number of ChAT-immunopositive somata. A decrease in ChAT synthesis has been reported in motoneurons after axotomy (Hoover and Hancock, 1985). Conceivably, then, a decrease in ChAT synthesis sufficient to eliminate detectable ChAT immunoreactivity in a proportion of the surviving motoneurons could result in the counts of Nissl-stained somata exceeding the number of ChAT + somata in the same nucleus. Hence, the counts of Nisslstained somata and ChAT + somata on immediately adjacent sections taken through the length of the facial nuclei allow for the differentiation of a loss of ChAT immunoreactivity from motoneuronal death caused by the axotomy (see Seniuk et al., 1990; Tatton and Greenwood, 1991; Tatton et al., 1991; Salo and Tatton, 1992). The remaining third of the serial sections were freeze dried and frozen for other studies.

Somata containing nucleoli on ChAT-immunoreacted sections were counted using interference-contrast optics, while somata in Nissl-stained sections were counted in the facial nuclei using the nuclear size criteria developed by Oppenheim to differentiate motoneurons from interneurons and glial cells in the brachial and lumbar spinal gray matter of the rat (Oppenheim, 1986). Somata were counted only if they contained a nucleolus.

$M A O$ inhibition. P14 rats wcre injected with $S(+)$-deprenyl, $R(-)$ deprenyl, or saline and a period of $4 \mathrm{hr}$ was allowed to pass before their subsequent death. At this time their brains were rapidly dissected out, and the portion of the brainstem between the upper mesencephalon and the medullary spinal junction was separated from the overlying cerebellum and isolated, rapidly frozen on dry ice, and stored at $-80^{\circ} \mathrm{C}$ until assayed for MAO activity as described by $\mathrm{Yu}$ (1986). Briefly, enzyme preparations of the above tissue were incubated at $37^{\circ} \mathrm{C}$ for 30 $\mathrm{min}$ in the presence of radiolabeled serotonin $(5-\mathrm{HT} ; 0.0005 \mathrm{M})$ or 2-phenylethylamine (2-PEA; $0.00001 \mathrm{~m}$ ) in a final volume of $200 \mu \mathrm{l}$. The reaction was terminated by the addition of $200 \mu \mathrm{l} 2 \mathrm{M}$ citric acid. The oxidized products were extracted into $1 \mathrm{ml}$ of toluene:ethyl acetate $(1: 1 \mathrm{v} / \mathrm{v})$ and radioactivity was assessed in $600 \mu \mathrm{l}$ of this extract by scintillation counting.

Reagents. Anti-ChAT antibody was purchased from Chemicon and goat anti-rabbit $\operatorname{IgG}$ and avidin-HRP complex was purchased from Vector Laboratories (Dimension Laboratories). $R(-)$-deprenyl and $S(+)$ deprenyl used in experiments carried out in parallel and employed for all results reported below were purchased from RBI Inc. (Natick, MA). The MAO substrates used for the radioenzymatic determination of $\mathrm{MAO}-\mathrm{A}$ and MAO-B activities, respectively, were ${ }^{14} \mathrm{C}-5-\mathrm{HT}$ and ${ }^{14} \mathrm{C}$ 2-PEA, both obtained from New England Nuclear.

Statistics. The counts of neuronal somata for the unlesioned, lesioned, saline-treated, and deprenyl-treated animals; the ChAT-immunoreacted and Nissl-stained sections; and the brainstem MAO-A and MAO-B activity measures for the saline-treated and deprenyl-treated animals were pairwise evaluated using the Mann-Whitney $U$ test (Siegel, 1956). Significance was taken when the probability that the groups were drawn from the same population was less than 0.05 . (The probability of a given experimental group being drawn from the corresponding saline control is presented beside individual data points shown on Figs. 4 and 6.)

\section{Results}

Stereospecificity of deprenyl-induced rescue of dying facial motoneurons

Figure 1 presents interference-contrast photomicrographs of typical ChAT-immunoreacted and Nissl-stained consecutive 

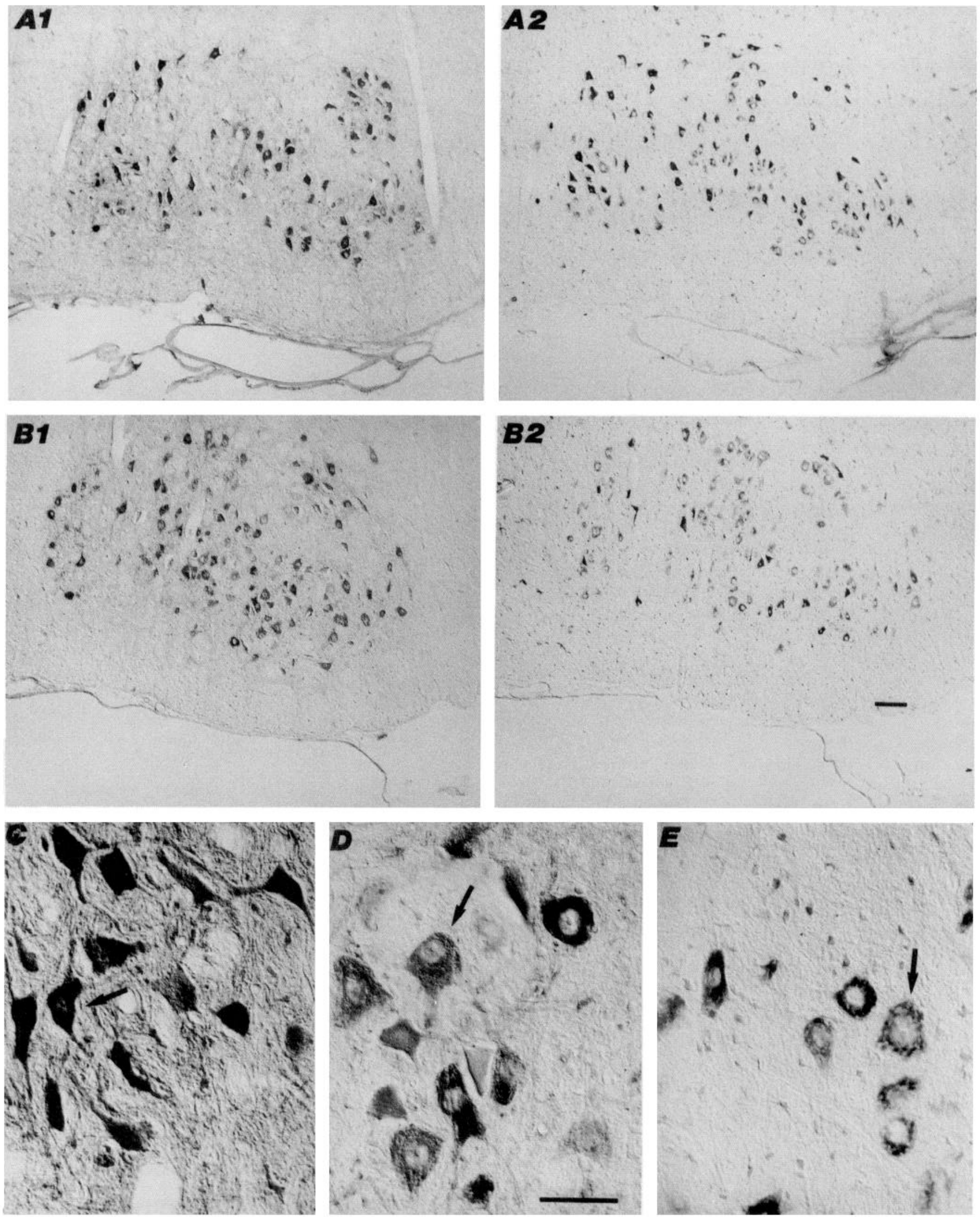

Figure 1. Photomicrographs of interference-contrast images of facial nuclei ipsilateral to a facial nerve section. The low-power photomicrographs were taken from sections through the right facial nuclei $21 \mathrm{~d}$ after a transection of the right facial nerve at P14. $A 1$ and $B 1$ are for sections immunoreacted for ChAT, while $A 2$ and $B 2$ are for Nissl-stained sections immediately adjacent to $A 1$ and $B 1$, respectively. $A 1$ and $A 2$ are sections from a saline-treated animal, while $B I$ and $B 2$ are from an animal treated with $0.01 \mathrm{mg} / \mathrm{kg}$ of $R(-)$-deprenyl. $C$ and $D$ present medium-power photomicrographs of a ChAT-immunoreacted motoneuron, while $E$ presents Nissl-stained motoneuron. The arrows mark the typical nucleoli used to count the somata. Scale bars: $B 2,100 \mu \mathrm{m}$ for $A 1, A 2, B 1$, and $B 2 ; D, 50 \mu \mathrm{m}$ for $C-E$. 

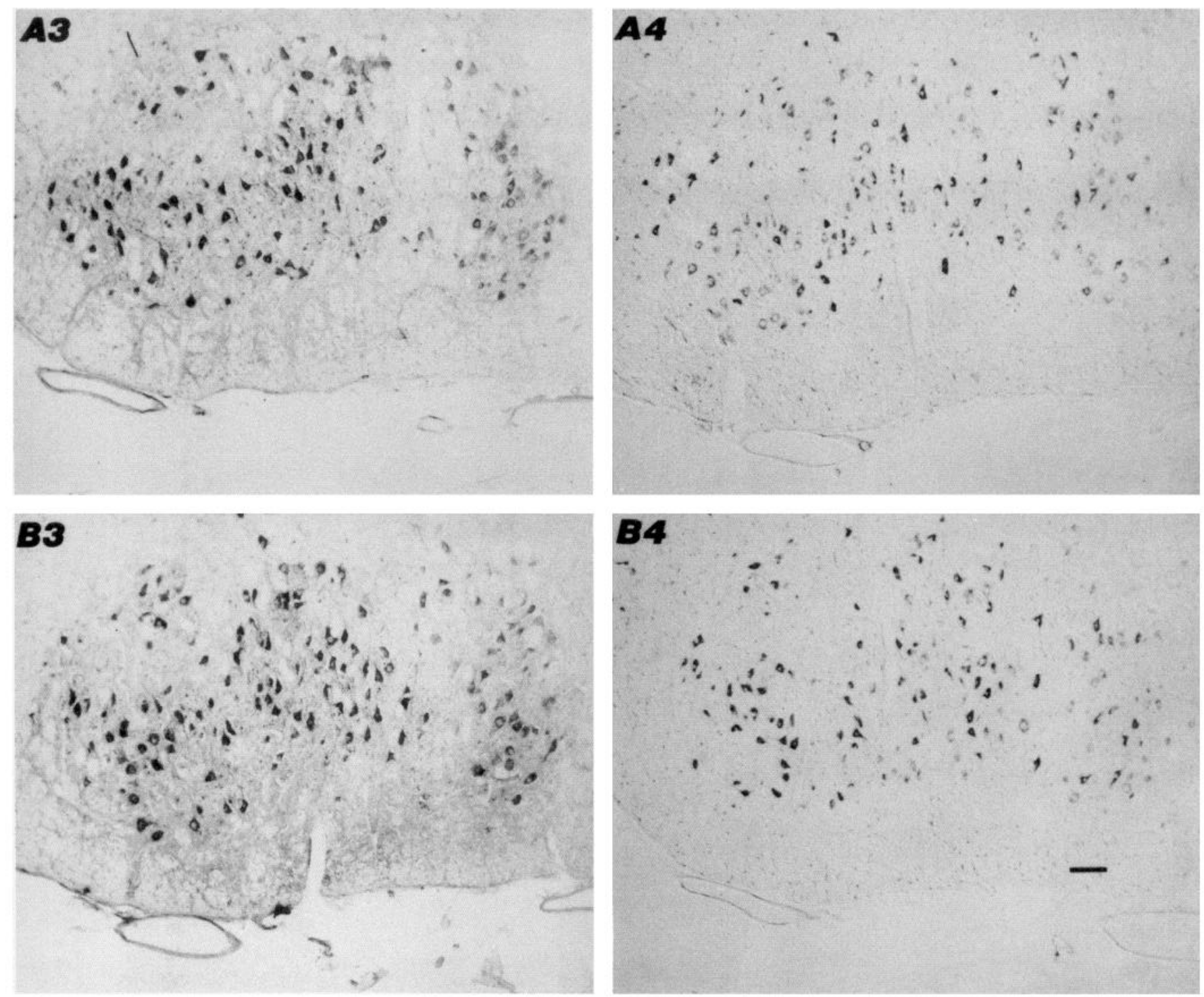

Figure 2. Photomicrographs of interference-contrast images of facial nuclei contralateral to a facial nerve section. The low-power photomicrographs were taken from sections through the left facial nuclei $21 \mathrm{~d}$ after a section of the right facial nerve at P14. $A 3$ and $B 3$ are for sections immunoreacted for ChAT, while $A 4$ and $B 4$ are for Nissl-stained sections immediately adjacent to Figure $1, A 1$ and $B 1$, respectively. $A 3$ and $A 4$ are from the contralateral sides of sections shown in Figure $1, A 1$ and $A 2$, while $B 3$ and $B 4$ are from the contralateral sides of sections shown in Figure $1, B 1$ and $B 2$. Scale bar, $100 \mu \mathrm{m}$.

sections of rat facial nuclei ipsilateral to a facial nerve transection. In Figure 1, the sections in $A 1$ and $A 2$ were from salinetreated animals, while the sections in $B 1$ and $B 2$ were from animals treated with the $0.01 \mathrm{mg} / \mathrm{kg} / 2 \mathrm{~d}$ of $R(-)$-deprenyl. The sections were taken at about the same rostrocaudal level of the facial nuclei in the two differently treated animals. Note the apparent similarity of the number and location of somata in the adjacent ChAT-immunoreacted and Nissl-stained sections (Fig. $1 A 1, A 2, B 1, B 2)$. The high-power photomicrographs in Figure 1, $C$ and $D$, are included to illustrate the nucleoli that were easily apparent on interference-contrast microscopy, and were used to count the facial motoneuron somata in ChAT-immunoreacted sections, while Figure $1 E$ shows Nissl-stained motoneurons meeting the nucleolar and nuclear size criteria for motoneurons (Oppenheim, 1986). Somata that did not include a nucleolus were not counted to avoid double counting the somata of a single neuron. Using nuclear size and nucleolar criteria, the counts for Figure $1, A 1, A 2, B 1$, and $B 2$, were $11,13,22$, and 23 , respectively.

Figure 2 presents photomicrographs from the same sections but from facial nuclei contralateral to those shown in Figure 1. In Figure 2, $A 3$ (ChAT immunoreacted) and $A 4$ (Nissl stained) are for a saline-treated animal, while $B 3$ (ChAT immunoreacted) and $B 4$ (Nissl stained) are for a $0.01 \mathrm{mg} / \mathrm{kg} R(-)$-deprenyltreated animal. Again, note the apparent correspondence of the motoneuron numbers in the immediately adjacent ChAT-immunoreacted and Nissl-stained sections.

Figure 3 presents overlaid longitudinal plots of the rostrocaudal distribution of ChAT-immunopositive somata in facial nuclei of P35 rats. Each panel presents overlaid plots for six different animals, with the values for each animal represented by a different symbol. The points present the counts of ChATimmunopositive somata through the full length of each facial nucleus and the area under each plot estimates the total count 
Figure 3. Rostrocaudal facial nucleus distributions of ChAT-immunoreactive somata. Each longitudinal rostrocaudal graph of ChAT + somal distributions includes values for six different animals. The points for each animal are represented by a different symbol. Each point presents the counts for the one in three $10 \mu \mathrm{m}$ serial sections that were immunoreacted for ChAT. No adjustments were made to the count values.

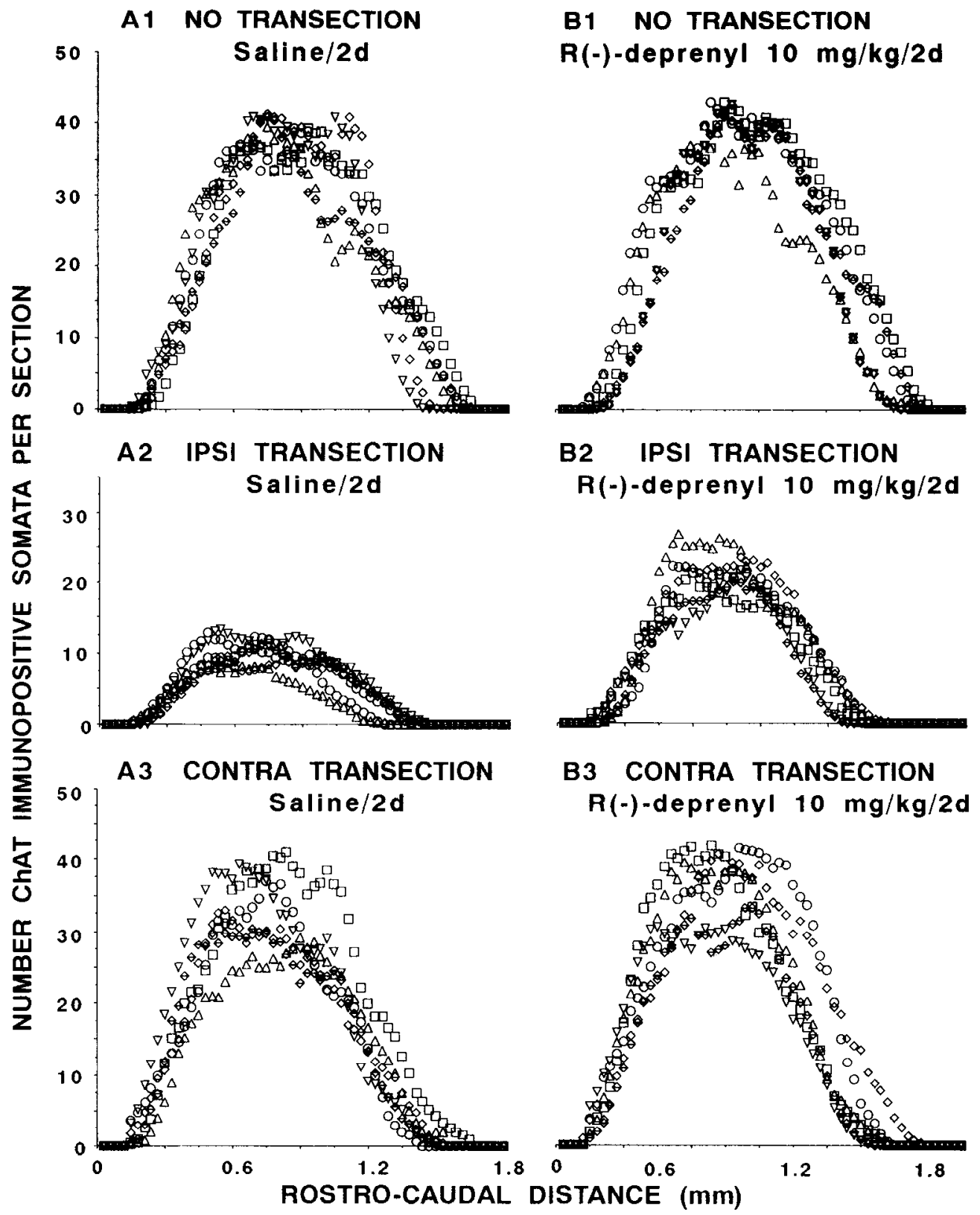

for one-third of the sections in each facial nucleus. Figure 4 depicts the mean \pm SEM values for the counts of ChAT + somata versus $\log _{10}$ dose for the different treatment groups ( $n$ = 6-9 animals in each group).

Figure 3, $A 1$ and $A 2$, presents overlaid longitudinal plots for animals that did not undergo facial nerve transection but were treated with saline (Fig. $3 A 1$ ) or $10 \mathrm{mg} / \mathrm{kg}$ of $R(-)$-deprenyl (Fig. 3A2) every second day from $\mathrm{P} 14$ to $\mathrm{P} 35$. They illustrate the reproducibility of the ChAT + somal counts from animal to animal and that a high dose of $R(-)$-deprenyl $(10 \mathrm{mg} / \mathrm{kg} / 2 \mathrm{~d})$ did not alter the counts of ChAT + somata in unlesioned animals. A probability value of 0.967 was found on statistical comparison of the counts, which showed that treatment with the 10 $\mathrm{mg} / \mathrm{kg}$ dose of $R(-)$-deprenyl did not alter the numbers of $\mathrm{ChAT}+$ somata in the unlesioned animals.

Figure $3 A 2$ presents overlaid longitudinal plots constructed for facial nuclei ipsilateral to a facial nerve section, while those in Figure $3 A 3$ are for the contralateral nuclei in the same six saline-treated animals. The plots illustrate the reduction in the number of ChAT + somata ipsilateral to the facial nerve section and show that the loss involved the whole length of the nuclei. The corresponding points in Figure 4 show that an average of $24.7 \%$ of the ChAT + somata remained in the ipsilateral lesion, saline-treated group compared to the unlesioned, saline-treated group $(p<0.0001)$. The overlaid longitudinal plots in Figure $3 A 3$ also illustrate the more variable loss of ChAT + motoneuronal somata in the facial nucleus contralateral to the facial nerve section, which averaged $73.7 \%$ of the average value for the unlesioned, saline-treated group. This value represented a statistically significant reduction in the number of ChAT + motoneurons in the facial nuclei contralateral to the facial nerve sections ( $p=0.026)$ when compared to the saline, unlesioned group.

The overlaid plots in Figure 3, $B 2$ and $B 3$, illustrate the in- 
creased number of ChAT + motoneuron somata in all portions of the nuclei induced by treatment with $10 \mathrm{mg} / \mathrm{kg}$ of $R(-)$ deprenyl every $2 \mathrm{~d}$. The corresponding points in Figure 4 show that the $10 \mathrm{mg} / \mathrm{kg} / 2 \mathrm{~d} R(-)$-deprenyl treatment increased the average percentage of ChAT + motoneuron somata in the ipsilateral facial nuclei from $24.7 \%$ to $48.5 \%(p=0.002)$ and from $73.7 \%$ to $91.6 \%(p=0.043)$. The remaining points in Figure 4 show that a dose of $R(-)$-deprenyl of $0.001 \mathrm{mg} / \mathrm{kg} / 2 \mathrm{~d}$ did not increase the percentage of ipsilateral $(25.1 \%)$ or contralateral $(78.5 \%) \mathrm{ChAT}+$ motoneuron somata, while the 0.005 and the $0.01 \mathrm{mg} / \mathrm{kg} / 2 \mathrm{~d}$ doses of $R(-)$-deprenyl both significantly increased the percentage of ChAT + ipsilateral somata $(51.5 \%)$. The $0.01 \mathrm{mg} / \mathrm{kg} / 2 \mathrm{~d}$ dose also significantly increased the percentage contralateral ChAT + somata $(91.7 \%)$, but the counts for the $0.005 \mathrm{mg} / \mathrm{kg} / 2 \mathrm{~d}$ dose did not reach significance $(86.3 \%)$. The values in the parentheses next to the points in Figure 4 present the probability that values for each treatment group were drawn from the same population as the corresponding saline group.

Neither of the two doses of $S(+)$-deprenyl that were tested $(0.1$ and $10.0 \mathrm{mg} / \mathrm{kg} / 2 \mathrm{~d}$, respectively) increased the percentages of the ipsilateral ( $26.2 \%$ and $28.1 \%$, respectively) or the contralateral $(80.3 \%$ and $77.8 \%$, respectively) ChAT + somata above the values for their corresponding saline groups.

Figure 5 illustrates the relationships between the longitudinal rostrocaudal distributions constructed for the counts of the ChAT + somata and the Nissl-stained somata in the alternate serial sections of the same nuclei for four selected treatment groups, while Table 1 presents the mean \pm SEM values for the ChAT + and Nissl counts taken from the full length of the nuclei for all of the lesion and treatment groups. The plots in the left column of Figure 5 present typical representative examples of the longitudinal ChAT + and Nissl longitudinal counts for a single animal, while those in the right column present the mean $\pm \mathrm{SD}$ values for the longitudinal distributions calculated for the nuclei from six animals. Figure $5, A 1$ and $A 2$, presents distributions for unlesioned animals treated with saline. The distri-

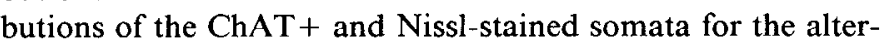
nating sections are very similar, indicating that almost all of Nissl somata identified as motoneuronal were also immunopositive for ChAT. Similarly, the values in Table 1 do not show a significant difference $(p=0.469)$ between the total Nissl and ChAT + counts for the six nuclei.

Figure 5, $B 1$ and $B 2$, presents similar longitudinal plots for facial nuclei ipsilateral to facial nerve sections that transected the peripheral axons of all of the motoneurons at P14. The similarity of the reduction in the numbers of both ChAT + and Nissl-stained somata in all longitudinal portions of the nuclei showed that a majority of motoneurons had died by $21 \mathrm{~d}$ after axotomy. Table 1 shows slightly smaller mean values for the $\mathrm{ChAT}+$ counts than the Nissl counts, but the values were not significantly different ( $p=0.265$ ). Figure 5, $C 1$ and $C 2$, presents longitudinal distributions for ipsilateral facial nuclei in animals treated with $0.01 \mathrm{mg} / \mathrm{kg} / 2 \mathrm{~d}$ of $R(-)$-deprenyl. The plots show an increase in the number of both ChAT + and Nissl-stained somata in all portions of the nuclei, illustrating that the $R(-)$ deprenyl has approximately doubled the survival of the motoneurons. Table 1 shows that the increase is reflected similarly in the mean ChAT + and Nissl somal counts.

Figure 5, DI and D2, shows longitudinal plots for ipsilateral facial nuclei in animals treated with $10 \mathrm{mg} / \mathrm{kg} / 2 \mathrm{~d}$ of $S(+)$-deprenyl. There does not appear to be any difference in the number
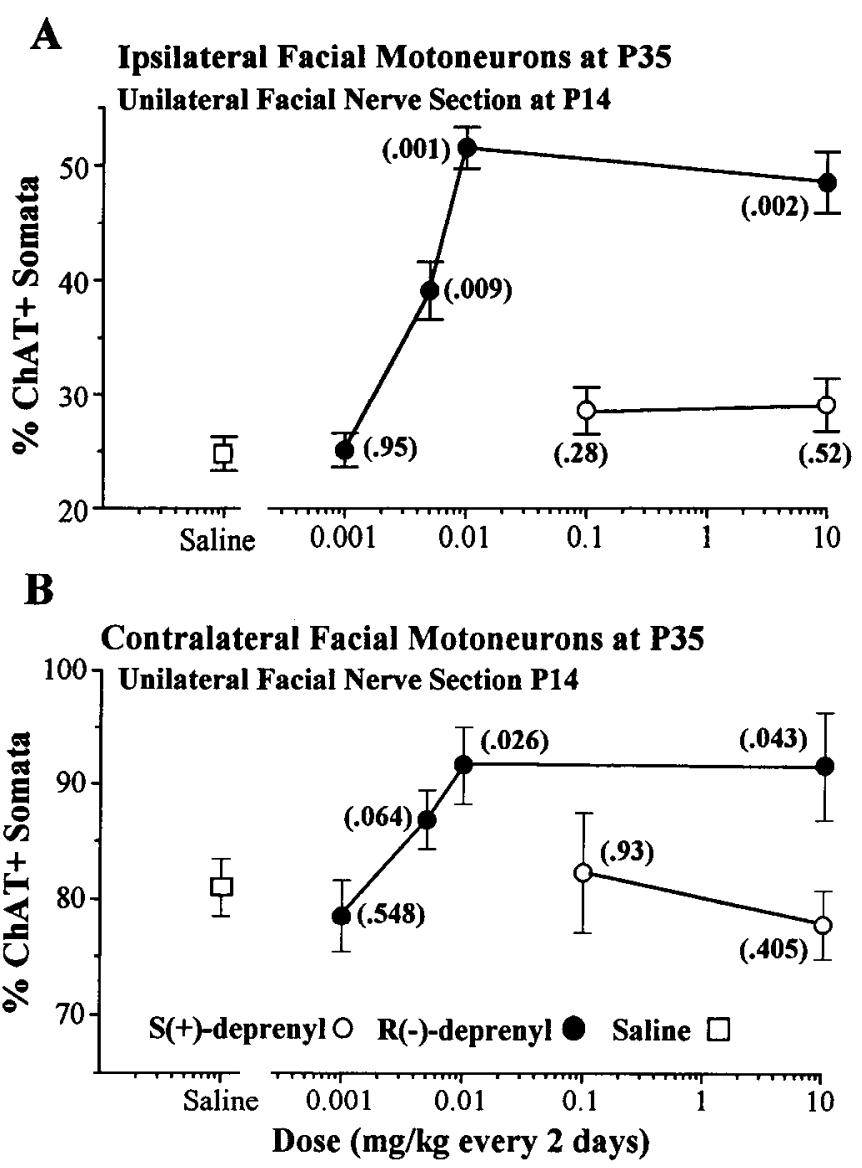

Figure 4. The effect of $R(-)$-deprenyl and $S(+)$-deprenyl on the survival of facial motoneurons following facial nerve section of $\mathrm{P} 14$ rats. Each point represents the mean counts of ChAT + somata from groups of six to nine animals, from every third section taken through the full length of every facial nucleus, and error bars represent SEMs. The values in parentheses adjacent to each point show the probability that the values could be drawn for the same population as the saline controls. The $\mathrm{ED}_{50}$ for rescue by $R(-)$-deprenyl was $0.005 \mathrm{mg} / \mathrm{kg} / 2 \mathrm{~d}$, while $10 \mathrm{mg} / \mathrm{kg} / 2 \mathrm{~d}$ of $S(+)$-deprenyl did not increase survival.

of surviving motoneurons from that shown for the saline-treated animals. Table 1 confirms that both the ChAT + and the Nissl counts did not show an increase for the highest dose of $S(+)$ deprenyl when compared to the corresponding saline values. The values in Table 1 establish that the ChAT values at P35 reflected death of the facial motoneurons rather than a loss of ChAT immunoreactivity, and that doses of $R(-)$-deprenyl of 0.01 and $10.0 \mathrm{mg} / \mathrm{kg} / 2 \mathrm{~d}$ increased the survival of the motoneurons while a $0.001 \mathrm{mg} / \mathrm{kg} / 2 \mathrm{~d}$ dose of $R(-)$-deprenyl or 0.1 or $10.0 \mathrm{mg} / \mathrm{kg} / 2 \mathrm{~d}$ doses of $S(+)$-deprenyl did not increase the survival.

\section{Sensitivity of deprenyl-mediated inhibition of $P 14$ rat brainstem $M A O-B$ and $M A O-B$}

The results obtained for MAO-B activity in the P14 brainstem are presented in Figure $6 B$, and those for MAO-A activity in Figure $6 \mathrm{~A}$. Figure $6 \mathrm{~A}$ shows that MAO-A activity was not significantly reduced by either enantiomer until doses of 10-50 $\mathrm{mg} / \mathrm{kg}$ were reached. The values in parentheses near each point present the $t$ test probability that the deprenyl-treated values were drawn from the corresponding saline-treated group.

The plot in Figure $6 B$ shows that both enantiomers inhibit 


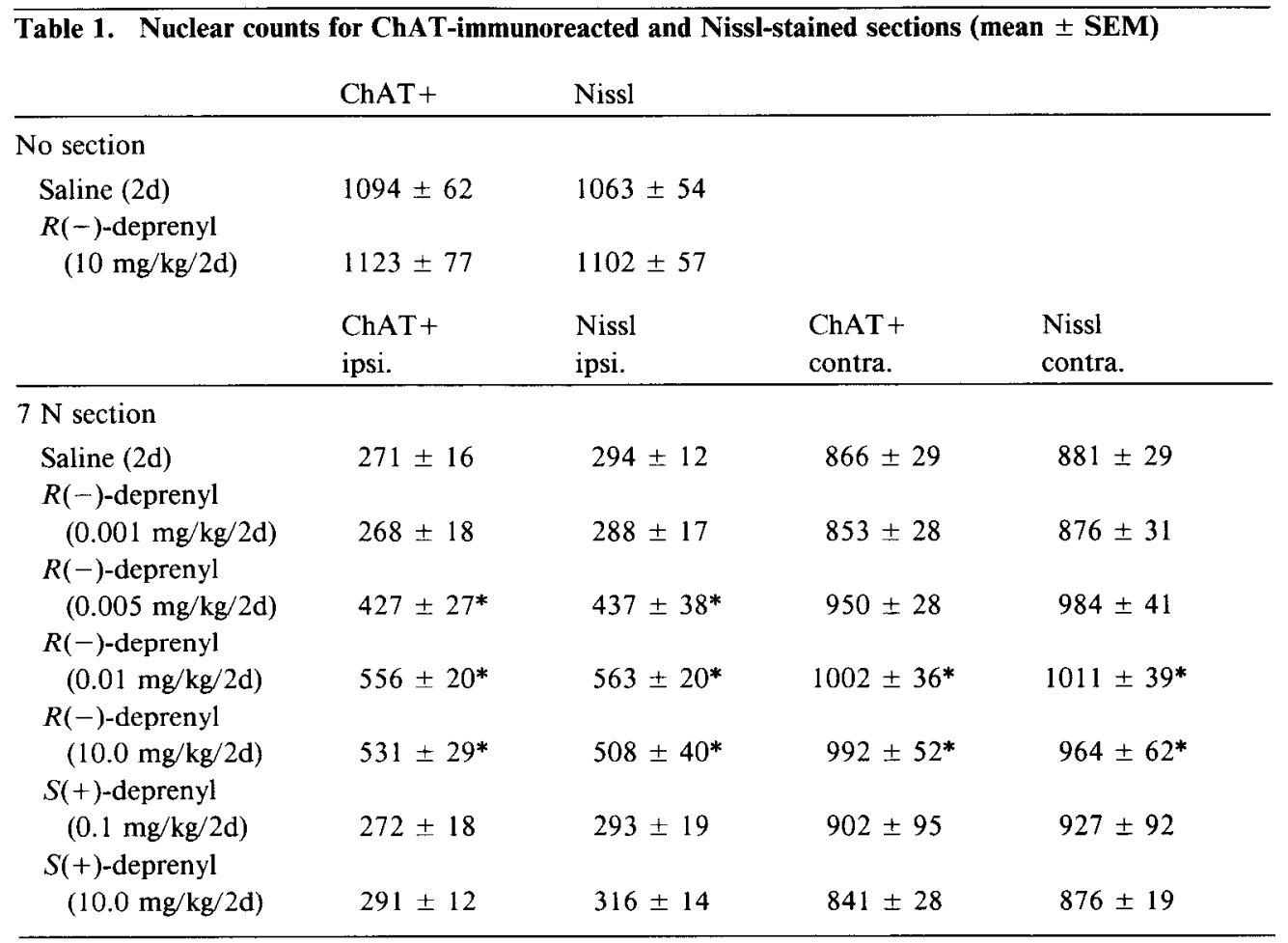

* Probability of being drawn from corresponding saline group is less than 0.05

MAO-B activity over different but overlapping dosage ranges. The spacing of dosage values according to decades does not allow us to define exactly the levels of MAO-B activity for doses that were not tested, but it is sufficient to estimate an $\mathrm{ED}_{50}$ value for $R(-)$-deprenyl of about $0.1 \mathrm{mg} / \mathrm{kg}$, which is lower than the value reported for adult rodents of $0.5 \mathrm{mg} / \mathrm{kg}$. The $\mathrm{ED}_{50}$ value for $S(+)$-deprenyl in the P14 brainstem was approximately 2 $\mathrm{mg} / \mathrm{kg}$. Since the affinity, in vitro, of the $(+)$-enantiomer $[S(+)$ deprenyl] for MAO-B is reportedly 10-20-fold lower than that of the (-)-enantiomer in brain tissue from the adult rat (Robinson, 1985), the difference we have found in the intact P14 brainstem appears similar.

\section{Discussion}

Neuronal death is difficult to establish conclusively. Immunocytochemistry for marker proteins is essential to identify specific neuronal populations but suffers from the limitation that damaged nerve cells, like motoneurons, often decrease or halt the synthesis of some proteins (Hoover and Hancock, 1985) while increasing the synthesis of other proteins (Tetzlaff et al., 1988, 1991). Hence, a loss of immunoreactive somata may indicate neuronal death or a reactive decrease in protein synthesis. Motoneuronal somata can be premarked by the retrograde transport of an agent from their terminal areas (see Rootman et al., 1981) and the number of remaining premarked somata used to estimate neuronal death (Crews and Wigston, 1990). The technique carries the limitation that the entire population may not transport the marking substance, either due to incomplete delivery of the agent to the target tissues or due to inadequate uptake or retrograde transport by some of the neurons. If retrograde transport of a premarker is combined with immunocytochemistry for a marker protein (Tatton et al,, 1991), it can be used to determine if a loss of immunoreactivity contributes to a reduc- tion in the counts of immunoreactive somata but cannot offer absolute values for neuronal death unless the entire neuronal population is shown to have transported the premarker (Tatton et al., 1991). Because the facial muscles are widely distributed over the rat face and adequate filling of all of the muscles with a premarker is difficult without extensive surgery, we chose to complement identification with a ChAT antibody with Nissl stain identification.

Counts of Nissl-stained somata can by themselves provide a good index of combined neuronal and glial loss in a nucleus or region but are complicated in terms of deducing neuronal death by possible atrophic changes in somal or nuclear size. Hence, atrophic neurons may no longer meet size criteria used to identify them. In the present study, we used the criteria of Oppenheim (1986) to identify motoneurons on serial sections through the length of each facial nucleus. In order to support the validity of the Nissl values, we used ChAT immunocytochemistry on alternate sections to those that were Nissl stained to identify motoneurons and complement the Nissl counts. Together, the ChAT + and Nissl-stained somal counts showed that virtually all of the somata meeting the Nissl criteria for motoneurons were immunoreactive for ChAT at $21 \mathrm{~d}$ after the facial nerve sections. This combined approach serves to validate the Oppenheim criteria for identifying Nissl-stained motoneurons and indicates that a reduction of ChAT + somata due to a loss or reduction in ChAT synthesis was not a significant contributor to our estimates of neuronal death by $21 \mathrm{~d}$ after the facial nerve sections. It suggests that the facial motoneurons that had lost sufficient ChAT synthesis to be immunocytochemically undetectable following axotomy (Hoover and Hancock, 1985) either had died or had recovered ChAT synthesis by $21 \mathrm{~d}$ after the axotomy.

The ability of deprenyl to induce increased survival of axotomized facial motoneurons is restricted to the $(-)$-enantiomer 


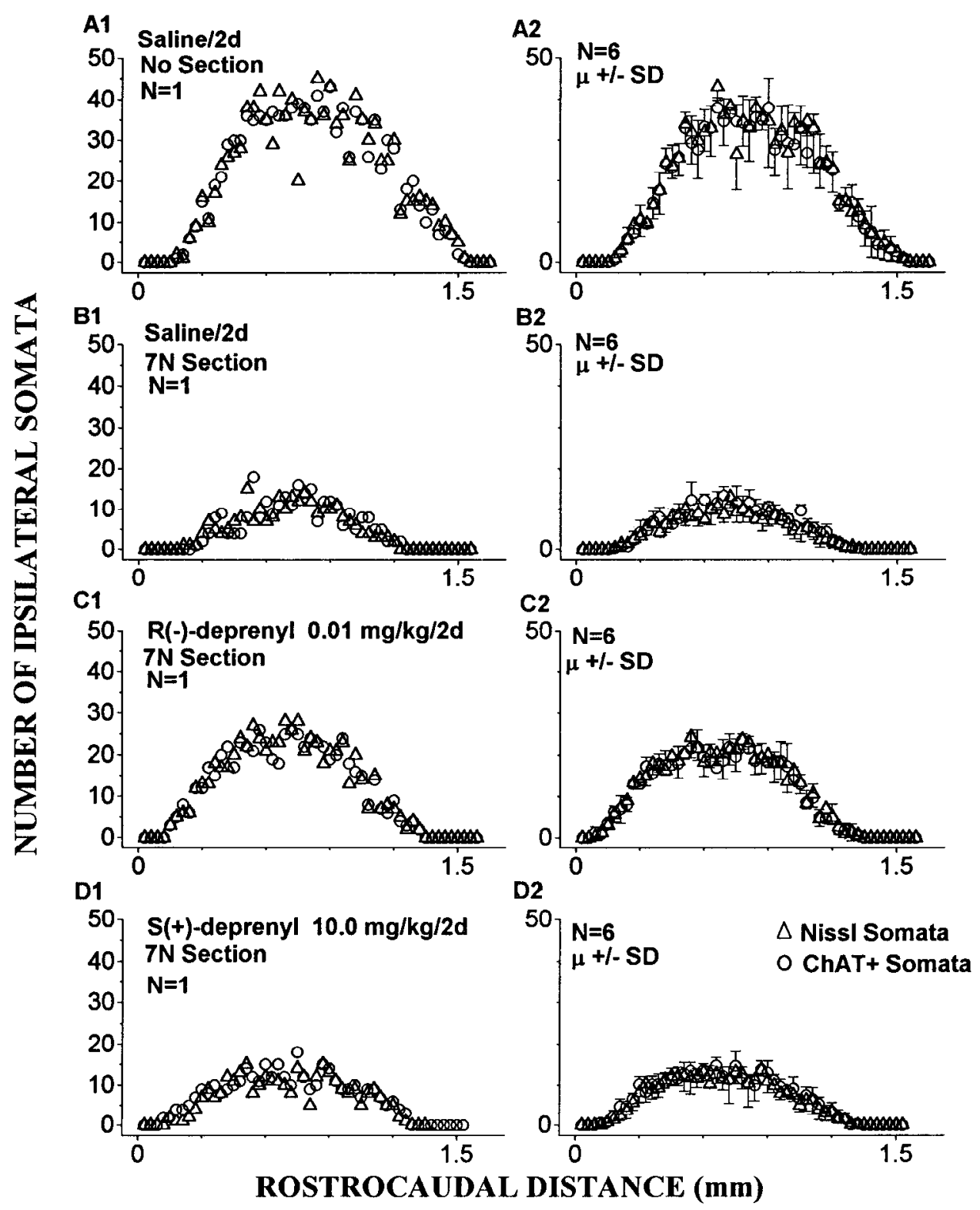

Figure 5. Comparison of longitudinal ChAT and Nissl counts of somata through the full length of facial nuclei. The figure shows superimposed longitudinal counts of ChAT + somata and Nissl-stained somata identified by the nuclear criteria of Oppenheim. The left pancls $(A 1-D I)$ show counts through a representative single nucleus, whereas the right panels represent the mean $\pm \mathrm{SD}$ values for counts obtained for six different animals. The plots show that $R(-)$-deprenyl increased motoneuron survival but $S(+)$-deprenyl did not. of the molecule over the dosage range tested in this study. This requirement for the $(-)$-stereoisomer appears to preclude the participation of MAO-B inhibition in the rescue mechanism. The data show that the threshold value for the $R(-)$-deprenylinduced rescue response must lie between $0.001 \mathrm{mg} / \mathrm{kg} / 2 \mathrm{~d}$ and $0.01 \mathrm{mg} / \mathrm{kg} / 2 \mathrm{~d}$ with an $\mathrm{ED}_{50}$ of about $0.005 \mathrm{mg} / \mathrm{kg} / 2 \mathrm{~d}$. Two dosages of $R(-)$-deprenyl, that is, $0.01 \mathrm{mg} / \mathrm{kg} / 2 \mathrm{~d}$ and $10 \mathrm{mg} /$ $\mathrm{kg} / 2 \mathrm{~d}$, were similarly potent in inducing increased motoneuronal survival. The $0.01 \mathrm{mg} / \mathrm{kg}$ dose of $R(-)$-deprenyl did not produce statistically significant inhibition of MAO-B while the $10.0 \mathrm{mg} / \mathrm{kg}$ dose caused at least $70 \% \mathrm{MAO}-\mathrm{B}$ inhibition. The $10 \mathrm{mg} / \mathrm{kg} / 2 \mathrm{~d}$ dose of $S(+)$-deprenyl did not induce an increase in motoneuronal survival but caused an average of $57 \% \mathrm{MAO}-\mathrm{B}$ inhibition. Hence, an $R(-)$-deprenyl dose insufficient to cause MAO-B inhibition did induce an apparently maximal increase in motoneuronal survival and a dose of $S(+)$-deprenyl that inhibited more than half of MAO-B activity did not increase motoneuronal survival.
It might be argued that the multipie doses of $R(-)$-deprenyl given every $2 \mathrm{~d}$ allowed significant MAO-B inhibition to accumulate over the $21 \mathrm{~d}$ of treatment (Waldmeier and Felner, 1978 ) and that the accumulated MAO-B inhibition induced the increased motoneuron survival. Several findings argue against that possibility. The facial motoneurons die quickly after axotomy at P14 such that $70 \%$ of the death has occurred by the third day after axotomy (W. Y. H. Ju, D. P. Holland, and W. $G$. Tatton, unpublished observations), and there is insufficient time for the doses to accumulate to a significant level of MAO-B inhibition. Furthermore, similar to the $S(+)$-deprenyl, doses producing $60 \%$ MAO-B inhibition while not increasing motoneuronal survival and doses of some other potent MAO inhibitors (e.g., iproniazid) that produce almost complete $\mathrm{M} \Lambda \mathrm{O}-\Lambda$ and MAO-B inhibition do not increase the survival of the axotomized motoneuron (F. Zhang, D. P. Holland, K. S. Ansari, and W. G. Tatton, unpublished observations).

The results appear to demonstrate that $\mathrm{P} 14$ rat brainstem 

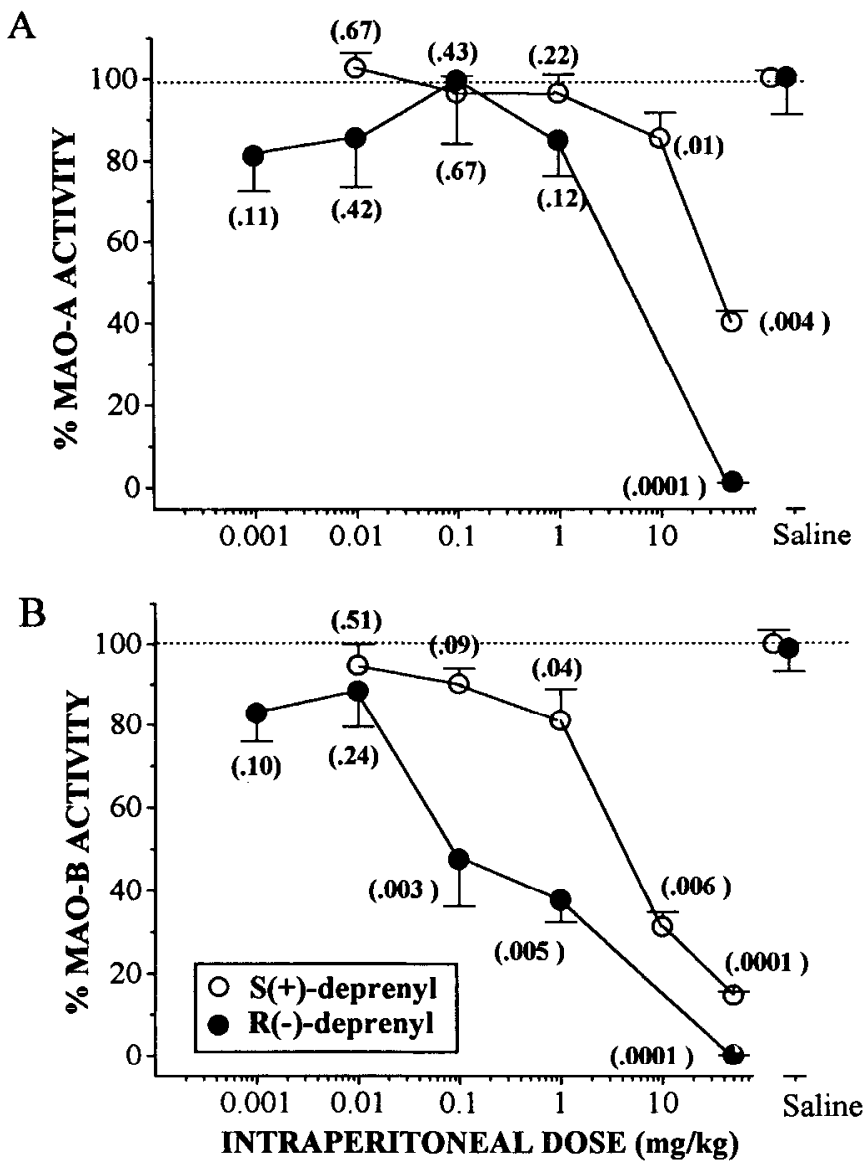

Figure 6. Inhibition of MAO-A and MAO-B activity in the P14 rat brainstem by $R(-)$-deprenyl and $S(+)$-deprenyl: plots of MAO-A activity $(A)$ and MAO-B activity $(B)$ for $\mathrm{P} 14$ rats treated with intraperitoneal doses of $R(-)$ - or $S(+)$-deprenyl ranging from 0.001 to $50.0 \mathrm{mg} /$ $\mathrm{kg}$. MAO activity was assayed at $4 \mathrm{hr}$ after the intraperitoneal doses. Each value presents the mean \pm SEM values normalized against the values for the corresponding saline controls and expressed as percentages. The values in parentheses adjacent to each point show the probability that the values could be drawn for the same population as the saline controls.

MAO-B activity is more sensitive to deprenyl than that in the adult brain. Increased sensitivity could be due to the different lipid microenvironment of MAO in the newborn brain. It is known that the kinetic parameters and sensitivity toward inhibitors of MAO are affected by the lipid components (Fowler and Oreland, 1980). Stroline-Benedetti and Dostert (1989) reviewed age-related changes in brain MAO activities and showed that rat brainstem MAO-B activity remains constant after 7-8 weeks of age. The relatively increased levels of MAO-B inhibition obtained in the P14 rats might also be rationalized on the basis that glial cell differentiation is known to occur over the first 3 postnatal weeks in the rat (Hirano and Goldman, 1988; Folk-seang and Miller, 1992) and is likely incomplete at P14. MAO-B is concentrated in astroglia (Westlund et al., 1988) and the brainstem concentrations of the mRNA for glial acidic fibrillary protein, the intermediate filament in astrocytes, is about $30 \%$ of adult values at P14 (W. G. Tatton and N. A. Seniuk, unpublished observations). Despite the increased sensitivity, the 20 -fold difference in sensitivity of brainstem MAO-B inhibition to the $(-)$ - and $(+)$-enantiomers is similar to that found in brain tissue from adult animals and appears in accord with the degree of stereosensitivity expected for the enzyme-substrate interaction (Stroline-Benedetti and Dostert, 1985).

The demonstration that the deprenyl-induced increase in the survival of immature motoneurons deprived of their musclederived trophic support shows pronounced stereospecificity and is not dependent on MAO-B inhibition could be compatible with an interaction involving $R(-)$-deprenyl that has characteristics more like those of classical receptor-ligand interactions than that of an enzyme-inhibitor interaction. Deprenyl binds to MAO-B irreversibly in a series of steps (Youdim, 1978). The inhibition is initiated by the formation of a noncovalent complex with MAO-B in a reversible, competitive step. This transient intermediate complex leads to the oxidation of deprenyl and the reduction of the FAD prosthetic group. The next step is irreversible and consists of the covalent binding of oxidized deprenyl to the N-5 position of the isoalloxazine ring of the FAD moiety (Robinson, 1985; Cesura et al., 1987; Heinonen et al., 1989). The modified flavin molecule reacts with a functional group on the enzyme surface through the reactive alkyl group, thus rendering the enzyme inactive toward normal substrate oxidation.

The doses of the two stereoisomers that we tested indicate at least a 2000 -fold preference for the induction of rescue by $R(-)$ deprenyl. The mirror-image rotation of the (+)-enantiomer might be assumed to impede access to the site involved in motoneuronal rescue while it is considerably less impeded in its access to the FAD site of MAO-B. MAO-B is concentrated in glial cells in rodents (Vincent, 1989) and is located in the outer leaflets of mitochondria, but the cellular localization of the site involved in the motoneuronal rescue is unknown. It is not impossible that the rescue could depend on an interaction with a subtype of MAO-B that possesses extremely high sensitivity to $R(-)$ deprenyl and mediates substrate oxidation in a special environment or mediates some unknown function that contributes to neuronal survival. Alternately, the rescue may involve interaction with a molecule that is unrelated to MAO-B. The structure of MAO-B may offer some clues to the site involved in the rescue. Analysis of the base sequences of the genomic DNA encoding MAO-A and MAO-B suggests the presence of two FAD-binding domains; cxon 12 encodes the FAD binding site and exons 1 and 2 may encode a recognition site that binds FAD noncovalently (Grimsby et al., 1991). The second site is reported to exhibit a high degree of homology with a number of other flavoproteins.

The finding that the rescue of the axotomized motoneurons appears independent of an interaction with MAO-B is in accord with work showing that $R(-)$-deprenyl was able to promote a marked increase in the survival of murine substantia nigra compacta neurons, after they had sustained lethal damage by MPTP, at dosages too low to cause any MAO inhibition (Tatton, 1993). Similarly, the finding that the rescue of axotomized motoneurons occurs with doses too small to cause MAO-A inhibition is in accord with the finding that clorgyline, a selective MAO-A inhibitor, did not rescue MPTP-damaged substantia nigra neurons (Tatton, 1993). We have found that pargyline, which inhibits both MAO-A and MAO-B and is structurally similar to deprenyl, increases the survival of the axotomized immature motoneuron but is considerably less effective on an equal molar basis (Tatton et al., 1992). (-)-Methamphetamine and (-)-amphetamine, the major metabolites of $R(-)$-deprenyl, do not increase the survival of the motoneuron (K. S. Ansari, F. Zhang, and W. G. Tatton, unpublished observations). Further work 
with structural analogs of $R(-)$-deprenyl will be required to determine which portion(s) of the molecule determines the stereospecific interaction that induces motoneuronal rescue.

One other study (Finnegan et al,, 1990) has shown that the protective action of deprenyl against DSP-4 (a noradrenergic toxin)-induced toxicity is not dependent upon MAO-B inhibition, as the duration of enzyme inhibition did not parallel the duration of the deprenyl-mediated protection. However, since $R(-)$-deprenyl has been shown to interfere with catecholamine uptake into neurons (Horsing et al., 1979; Hallman and Jonsson, 1984), the possibility that the results reported in that study represent deprenyl-mediated blockade of neuronal DSP-4 uptake cannot be excluded. Control experiments involving delayed administration of deprenyl similar to those used to establish a second action for $R(-)$-deprenyl in MPTP parkinsonism (Tatton and Greenwood, 1991) would be required to elucidate the action of deprenyl on DSP-4 toxicity.

The mechanism by which $R(-)$-deprenyl rescues the axotomized motoneuron is unknown. It would seem plausible, however, to suggest that deprenyl induces compensation for loss of targetderived trophic support. This does not imply that $R(-)$-deprenyl itself acts as a trophic factor but rather that it interferes with or triggers some event that supports the survival of motoneurons after the withdrawal of the trophic support. Recent research has shown that the neurotrophic factors bFGF (Grothe and Unsicker, 1992), BDNF (Sendtner et al., 1992; Yan et al., 1992), and CNTF (Sendtner et al., 1990) reduce axotomy-induced death of facial or hypoglossal motoneurons in neonatal or immature rats in experiments similar to ours with $R(-)$ deprenyl.

CNTF reportedly increased the survival of facial motoneurons axotomized at $\mathrm{P} 1$ from approximately $24 \%$ to about $80 \%$ (Sendtner et al., 1990) and BDNF increased the survival to about $55 \%$ at the same age (Sendtner et al., 1992; Yan et al., 1992). Direct comparison to our findings at $\mathrm{P} 14$ with $R(-)$-deprenyl may be complicated by the approximately $15-20 \%$ naturally occurring motoneuronal death that occurs between Pl and P8 in the rat (Rootman et al., 1981). Hence, motoneuronal death due to a loss of target-derived trophic support may be superimposed on naturally accurring motoneuronal death when axotomy is carried out at P1. bFGF increased the survival of hypoglossal motoneurons axotomized at $\mathrm{P} 7$ from about $12 \%$ to about 24\% (Grothe and Unsicker, 1992). In any case, by treating the animals with $R(-)$-deprenyl every second day, we achieved an increase in survival that is within the same range as that induced by the three neurotrophic factors.

Yet our schedule of treating the immature animals every 48 hr with the $R(-)$-deprenyl may not be optimal. We initially designed our experiments based on the premise that an action of $R(-)$-deprenyl would be dependent on MAO-B inhibition (Tatton and Greenwood, 1991; Salo and Tatton, 1992). The half-life of MAO-B inhibition by $R(-)$-deprenyl in rodents is 5-7 d (Heinonen and Lammintausta, 1991), so we reasoned that a dose every second day was adequate and would in fact cause the MAO-B inhibition to cumulate over the $21 \mathrm{~d}$ of treatment every second day (Tatton, 1993). The present study indicates that brain concentrations of $10^{-6} \mathrm{M}$ or less can induce increased survival of the axotomized motoneuron. The $10^{-6} \mathrm{M}$ concentration is based on the $0.01 \mathrm{mg} / \mathrm{kg}$ dosage and an assumption that MAO-B is equally distributed in the rat tissues. Since MAO-B is concentrated in hepatic cells and circulating cells like platelets to a greater extent than in brain tissues (Kalari et al., 1988;
Riachi and Harik, 1992), it is likely that brain concentrations are lower than those predicted on the basis of equal whole-body distribution. The half-life of $R(-)$-deprenyl in rodents is about $1.5 \mathrm{hr}$ (Heinonen et al., 1989); hence, the treatment schedules we have used to date have offered pulses of $R(-)$-deprenyl only every $48 \mathrm{hr}$ and yet have been effective at $0.01 \mathrm{mg} / \mathrm{kg}$. Continuous infusion of $R(-)$-deprenyl might induce greater survival of the axotomized motoneuron.

Given the similar dosages required for neuronal rescue and the independence of the increased survival from MAO-B inhibition, it is likely that the mechanism involved in the rescue of axotomized immature motoneurons is the same as that mediating the rescue of MPTP-damaged dopaminergic neurons (Tatton and Greenwood, 1991; Tatton, 1993). Similarly, an MAO-independent rescue mechanism could conceivably account for the reported slowing of the progression of $\mathrm{PD}$ and $\mathrm{AD}$ by $R(-)$-deprenyl (Tatton, 1993). A rescue mechanism as opposed to neuroprotection would not require a common basis for damage to the largely different neuronal populations that degenerate in the two diseases.

In conclusion, if the deprenyl-induced rescue of axotomized facial motoneurons does involve a high-affinity, stereospecific interaction with an as yet unknown site, the characterization and identification of the site could provide new insights into the processes that influence neuronal survival.

\section{References}

Allain H, Cougnard J, Neukirch H, Members F (1991) Selegiline in de novo Parkinson patients; the French multicenter trial (FMST). Acta Neurol Scand [Suppl] 136:73-78.

Bach AWJ, Lan NC, Johnson DL, Abell CW, Bembenek ME, Kwan S-E, Seeburg PH, Shih JC (1988) cDNA cloning of human liver monoamine oxidase A and B: molecular basis of differences in enzymatic properties. Proc Natl Acad Sci USA 85:4934-4938.

Birkmayer W, Riederer P, Youdim MBH, Linauet W (1975) The potentiation of the anti-akinetic effect of $L$-dopa treatment by an inhibitor of MAO-B, L-deprenyl. J Neural Transm 36:303-336.

Birkmayer W, Knoll J, Riederer P, Youdim MBH (1983) (-)-Deprenyl leads to prolongation of L-dopa efficacy in Parkinson's disease. Mod Probl Pharmacopsychiatry 19:170-177.

Campi N, Todeschini GP, Scarzella L (1990) Selegiline versus L-acetylcarnitine in the treatment of Alzheimer-type dementia. Clin Ther 12:306-314

Cesura AM, Galva MD, Imhof R, Da Prada M (1987) Binding of [ ${ }^{3} \mathrm{H}$ ]Ro 16-6491, a reversible inhibitor of monoamine oxidase type $B$, to human brain mitochondria and platelet membranes. J Neurochem 48:171-176.

Crews LL, Wigston DJ (1990) The dependence of motoneuron on their target muscle during postnatal development of the mouse. J Neurosci 10:1643-1653.

Demarest KT, Smith DJ, Azzaro AJ (1980) The presence of the type a form of mono amine oxidase EC-1.4.3.4 within nigro striatal dopamine containing neurons. J Pharmacol Exp Ther 215:461-468.

Engberg G, Elebring T, Nissbrandt H (1991) Deprenyl (selegiline), a selective MAO-B inhibitor with active metabolites; effects on locomotor activity, dopaminergic neurotransmission and firing rate of nigral dopaminergic neurons. J Pharmacol Exp Ther 259:841-847.

Falsaperla A, Monici PP, Oliani C (1990) Selegiline versus oxiracetam in patients with Alzheimer-type dementia. Clin Ther 12:376-384.

Finnegan KT, Skratt JJ, Irwin I, DeLanney LE, Langston JW (1990) Protection against DSP-4 induced neurotoxicity by deprenyl is not related to its inhibition of MAO B. Eur J Pharmacol 184:119-126.

Folk-seang J, Miller R (1992) Astrocyte precursors in neonatal spinal cord cultures. J Neurosci 12:2751-2764.

Fowler CJ, Oreland L (1980) The effect of lipid depletion on the kinetic properties of rat liver monoamine oxidase B. J Pharm Pharmacol 32: 681-688.

Goad DL, Davis CM, Liem P, Fuselier CC, McCormack JR, Olsen KM 
(1991) The use of selegiline in Alzheimer's patients with behavior problems. J Clin Psychol 52:342-345.

Grimsby J, Chen K, Wang L-J, Lan NC, Shih JC (1991) Human monoamine oxidase $A$ and $B$ genes exhibit identical exon-intron organization. Proc Natl Acad Sci USA 88:3637-3641.

Grothe C, Unsicker K (1992) Basic fibroblast growth factor in the hypoglossal system: specific retrograde transport, trophic and lesionrelated responses. J Neurosci Res 32:317-328.

Hallman H, Jonsson GH (1984) Pharmacological modification of the neurotoxic action of the noradrenaline neurotoxin DSP-4 on central noradrenaline neurons. Eur J Pharmacol 103:269-278.

Heinonen EH, Lammintausta R (1991) A review of the pharmacology of selegiline. Acta Neurol Scand 84:44-59.

Heinonen EH, Myllylla V, Sotaniemi K, Lamintausta R, Salonen JS, Anttila M, Savijärvi M, Kotila M, Rinne UK (1989) Pharmacokinetics and metabolism of selegiline. Acta Neurol Scand [Suppl] I26: 93-99.

Hirano M, Goldman JE (1988) Gliogenesis in the rat spinal cord: evidence for origin of astrocytes and oligodendrocytes from radial precursors. J Neurosci Res 21:155-167.

Hoover DB, Hancock JC (1985) Effect of facial nerve transection on acetylcholinesterase, choline acetyltransferase, and tritium quinuclidinyl benzilate binding in rat facial nuclei. Neuroscience 15:481-488.

Horsing LG, Magyar K, Tekes K, Vizi ES, Knoll J (1979) Inhibition of dopamine uptake by deprenyl in rat striatum: a possible correlate between dopamine uptake and acetyl choline release inhibition. Pol J Pharmacol Pharm 31:297-307.

Johnston JP (1968) Some observations upon a new inhibition of monoamine oxidase in brain tissue. Biochem Pharmacol 17:431-435.

Kalari RN, Mitchell MJ, Harik SI (1988) Monoamineoxidases of the human brain and liver. Brain 111:1441-1451.

Karoum F, Chuang LW, Eisler T, Calne DB, Liebowitz MR, Quitkin FM, Klein DF, Wyatt RJ (1982) Metabolism of (-)deprenyl to amphetamine and methamphetamine may be responsible for deprenyl's therapeutic benefit: a biochemical assessment. Neurology 32: 503-509.

Lieberman A, Fahn S, Olanow CW, Tetrud JW, Koller WC, Calne D, Fazzini EA, Muenter MD (1992) Does selegiline provide a symptomatic or a neuroprotective effect-discussion. Neurology 42:41-48.

Linder JC, Klemfuss H, Groves PM (1987) Acute ultrastructural and behavioral effects of 1-methyl-4-phenyl-1,2,3,6-tetrahydropyridine (MPTP) in mice. Neurosci Lett 82:221-226.

Mangoni A, Grassi MP, Frattola L, Piolti R, Bassi S, Motta A, Marcone A, Smirne S (1991) Effects of an MAO-B inhibitor in the treatment of Alzheimer's disease. Eur Neurol 31:100-107.

Martignoni E, Bono G, Blandini F, Sinforiani E, Merlo P, Nappi G (1991) Monoamines and related metabolite levels in the cerebrospinal fluid of patients with dementia of Alzheimer type: influence of treatment with L-deprenyl. J Neural Transm [Parkinson's Dis Dementia] 3:15-26.

Monteverde A, Gnemmi P, Rossi F, Monteverde A, Finali GC (1990) Selegiline in the treatment of mild to moderate Alzheimer-type dementia. Clin Ther 12:315-322.

Myllylä VV, Sotaniemi KA, Vuorinen JA, Heinonen EH (1992) Selegiline as initial treatment in de novo parkinsonian patients. Neurology 42:339-343.

Olanow CW, Calne D (1992) Does selegiline monotherapy in Parkinson's disease act by symptomatic or protective mechanisms? Neurology 42:13-26.

Oppenheim RW (1986) The absence of significant postnatal motoneuron death in the brachial and lumbar cord of the rat. J Comp Neurol 246:281-286.

Parkinson Study Group (1989) Effect of deprenyl on the progression of disability in early Parkinson's disease. N Engl J Med 321:13641371.

Parkinson Study Group (1993) Effects of tocopherol and deprenyl on the progression of disability in early Parkinson's disease. N Engl J Med 328:176-183.

Paterson IA, Juorio AV, Boulton AA (1990a) 2-Phenylethylamine: a modulator of catecholamine transmission in the mammalian central nervous system? J Neurochem 55:1827-1837.

Paterson IA, Juorio AV, Boulton AA (1990b) Possible mechanism of action of deprenyl in parkinsonism. Lancet 336:183.

Piccinin GL, Finali G, Piccirilli M (1990) Neuropsychological effects of L-deprenyl in Alzheimer's type dementia. Clin Neuropharmacol 13:147-163.
Poungvarin N, Viriyavejakul A (1990) L-Deprenyl therapy in Thai patients with Parkinson's disease before and after clinical trial of 50 patients. J Med Assoc Thail 73:381-386.

Riachi NJ, Harik SI (1992) Monoamine oxidases of the brains and livers of macaque and cercopithecus monkeys. Exp Neurol 115:212217.

Robinson JB (1985) Stereoselectivity and isoenzyme selectivity of monoamine oxidase inhibitors. Biochem Pharmacol 34:4105-4108.

Rootman DS, Tatton WG, Hay M (1981) Postnatal histogenetic death of rat forelimb motoneuron. J Comp Neurol 199:17-27.

Salo PT, Tatton WG (1992) Deprenyl reduces the death of motorneurons caused by axotomy. J Neurosci Res 31:394-400.

Schneider LS, Pollock VE, Zemansky MF, Gleason RP, Palmer R, Sloane RB (1991) A pilot study of low dose L-deprenyl in Alzheimer's disease. J Geriatr Psychiatry Neurol 4:143-148.

Sendtner M, Kreutzberg GW, 1 hoenen $H$ (1990) Ciliary neurotrophic factor prevents the degeneration of motor neurons after axotomy. Nature 345:440-441.

Sendtner M, Holtmann B, Kolbeck R, Thoenen H, Barde Y-A (1992) Brain-derived neurotrophic factor prevents the death of motoneuron in newborn rats after nerve section. Nature 360:757-759.

Seniuk NA, Tatton WG, Greenwood CE (1990) Dose-dependent destruction of the coeruleus-cortical and nigral-striatal projections by MPTP. Brain Res 527:7-20.

Shih JC (1991) Molecular basis of human MAO A and B. Neuropsychopharmacology 4:1-7.

Siegel S (1956) Non-parametric statistics for the behavioral sciences, pp 127-136. New York: McGraw-Hill.

Stroline-Benedetti M, Dostert P (1985) Stereochemical aspects of MAO interactions: reversible and selective inhibitors of monoamine oxidase. Trends Pharmacol Sci 6:246-251.

Stroline-Benedetti MS, Dostert P (1989) Monoamine oxidase, brain ageing and degenerative diseases. Biochem Pharmacol 38:555-561.

Sunderland T, Tariot PN, Cohen RM, Newhouse PA, Mellow AM, Mueller EA, Murphy DL (1987) Dose-dependent effects of deprenyl on CSF monoamine metabolites in patients with Alzheimer's disease. Psychopharmacology 91:293-296.

Tariot PN, Sunderland T, Weingartner H, Murphy DL, Wclkowtiz JA, Thompson K, Cohen RM (1987) Cognitive effects of L-deprenyl in Alzheimer's disease. Psychopharmacology 91:489-495.

Tatton WG (1993) Selegiline ((-)-deprenyl) can mediate neuronal rescue rather than neuronal protection. Mov Disord, in press.

Tatton WG, Greenwood CE (1991) Rescue of dying neurons: a new action for deprenyl in MPTP parkinsonism. J Neurosci Res 30:666672.

Tatton WG, Greenwood CE, Salo P, Seniuk NA (1991) Transmitter synthesis increases in substantia nigra neurons in aged mice. Neurosci Lett 131:179-182.

Tatton WG, Salo PT, Yu PH, Holland DP, Kwan MM, Ansari KS (1992) Both pargyline and selegiline reduce the death of immature motoneuron after axotomy. Soc Neurosci Abstr 18:47.

Tetrud JW, Langston JW (1989) The effect of deprenyl (selegiline) on the natural history of Parkinson's disease. Science 245:519-522.

Tetzlaff W, Bisby MA, Kreutzberg GW (1988) Changes in cytoskeletal proteins in rat facial nucleus following axotomy. J Neurosci 8:31913199.

Tetzlaff W, Alexander SW, Miller FD, Bisby MA (1991) Response of facial and rubrospinal neurons to axotomy changes in messenger RNA expression for cytoskeletal proteins and GAP-43. J Neurosci 11:25282544.

Vincent SR (1989) Histochemical localization of 1-methyl-4-phenyl$1,2,3,6$-tetrahydropyridine oxidation in the mouse brain. Neuroscience 28:189-199.

Waldmeier PC, Felner AE (1978) Deprenil, loss of selectivity for inhibition of b-type MAO after repeated treatment. Biochem Pharmacol 27:801-806.

Westlund KN, Denney RM, Rose RM, Abell CW (1988) Localization of distinct monoamine oxidase $\mathrm{A}$ and monoamine oxidase $\mathrm{B}$ cell populations in human brainstem. Neuroscience 25:439-456.

Yan Q, Elliot J, Snider WD (1992) Brain-derived neurotrophic factor rescues spinal motor neurons from axotomy-induced cell death. $\mathrm{Na}$ ture 360:753-755.

Yang S, Johannessen JN, Markey SP (1988) Metabolism of [C $\left.\mathrm{C}^{14}\right]$ MPTP in mouse and monkey implicates $\mathrm{MPP}^{+}$, and not bound metabolites, as the operative toxin. Chem Res Toxicol 1:228-233.

Youdim MBH (1978) The active centers of monoamine oxidase types 
A and B: binding with $\left({ }^{14} \mathrm{C}\right)$-clorgyline and $\left({ }^{14} \mathrm{C}\right)$-deprenyl. J Neural Transm 43:199-208.

Yu PH (1986) Neuromethods V: Neurotransmitter enzymes, pp 235248. Clifton, NJ: Humana.

Yu PH, Hertz L (1982) Differential development of type A and type
B monoamine oxidase of mouse astrocytes in primary cultures. $\mathrm{J}$ Neurochem 39:1492-1495.

Yu PH, Davis BA, Boulton AA (1992) Aliphatic propargylamines: potent selective irreversible monoamine oxidase B inhibitors. J Med Chem 35:3705-3713. 